\title{
Prácticas Religiosas Y ReCONFIGURACIÓN DEL ESPACIO PÚBLICO EN COMUNIDADES DE MICHOACÁN
}

\section{Religious Practices and Reconfiguration of Public Space in Communities of Michoacan}

\section{José Eduardo Zárate Hernández ${ }^{1}$}

Resumen: En este ensayo se explora la relación dinámica entre religiosidad y civilidad en las comunidades michoacanas contemporáneas. Con este propósito se discute la relación entre lo secular y el espacio público en términos amplios, referidos no solamente a las sociedades burguesas urbanas, sino a la sociedad rural de nuestros días. Se revisan los principales procesos de cambio y se describe la manera en que el lenguaje religioso expresa los intereses de las comunidades locales inmersas en el cambiante mundo actual.

Palabras clave: religiosidad, secularismo, modernización.

Abstract: This essay explores the dynamic relationship between religion and civility in contemporary communities in Michoacan. For this purpose, the relationship between the secular and the public space is discussed in broad terms, referring not only to urban bourgeois societies, but also to the rural society of today.

\footnotetext{
${ }^{1}$ Agradezco a Jesús Solís Cruz sus amables sugerencias y a los dictaminadores anónimos sus críticas y comentarios que ayudaron a mejorar el texto.

Maestro en Antropología Social por El Colegio de Michoacán y Doctor en Ciencias Sociales por el CIESAS-Occidente. Líneas de investigación: Sociedad, ideología y concepciones del Mundo. Proyecto: Trasnacionalización, etnicidad y movimientos emergentes en el centro de Michoacán. El Colegio de Michoacán.

Correo electrónico: zarate@colmich.edu.mx

Fecha de recepción: 2604 15; Fecha de aceptación: 051215.
}

(c)) EY-Nc-ND Páginas 103-130. 
The main processes of change are reviewed and the way religious language expresses the interests of local communities immersed in today's changing world is described.

Keywords: religiosity, secularism, modernization.

\section{Introducción}

El objetivo de este ensayo es mostrar la importancia de las prácticas religiosas en la conformación de comunidades indígenas modernas, abiertas y plurales, en las que es posible encontrar conviviendo diferentes proyectos de sociedad y en las que aparecen nuevos actores sociales que renuevan los mecanismos comunales de participación. El problema es que tradicionalmente se ha entendido la religiosidad popular como vinculada al tradicionalismo, la obediencia y el conservadurismo, prácticas que se consideran conducen al cierre social. Lo que sin duda constituye una gran generalización que sólo oscurece el entendimiento de las múltiples maneras en que la religiosidad y la civilidad se conjugan en la conformación de nuevas formas de convivencia. El origen de esta reflexión se encuentra en el estudio, en varias comunidades de la región purhépecha, de un sistema de fiestas populares relacionadas con el culto al Niño Jesús, que se ha extendido de manera notable en las últimas décadas. Su marcado crecimiento y la importante participación "voluntaria" de grandes contingentes de personas en las festividades, así como de nuevos actores, es lo que nos ha dado pie para repensar el papel que la religiosidad tiene en la sociedad moderna. Es importante señalar que existen varios estudios relacionados con el culto al Nińo Dios, llamado Niñopa, en la localidad Xochimilco, en especial de Salles y Valenzuela, 1997; y Blasquez, 2001. Estos trabajos de alguna manera han reflexionado sobre el significado de este culto en una sociedad urbana y moderna como la ciudad de México, pero no en un ámbito rural, que está viviendo importantes transformaciones como el de Michoacán.

No obstante hablar de comunidades modernas y en cierta medida plurales, implica el reconocimiento de la existencia, así sea incipiente, 
de un espacio público en localidades que supuestamente mantienen cierta homogeneidad y no muestran marcadas diferencias o divergencias culturales y políticas. Por el contrario, el espacio público es el lugar donde se expresan las diferencias, ocurre el debate y surgen los acuerdos en relación con un tema común o a lo que cada comunidad considera el bien común. ${ }^{2}$ También implica cuestionar la idea de que cuando hablamos de un espacio público nos estamos refiriendo a un ámbito estrictamente secular. ${ }^{3}$ Asad (2003) ha criticado que se considere el secularismo como la quinta esencia de la esfera pública en las sociedades modernas, cuando hay otras expresiones que no se deberían de dejar de lado, como las acciones afirmativas y los microdebates que ocurren en ámbitos locales y que con el paso del tiempo se van convirtiendo en la nueva realidad o en parte de un nuevo orden social. Entre estas acciones y microdebates aparece en las sociedades modernas claramente el interés por el mantenimiento y la renovación de las prácticas religiosas y de ciertas manifestaciones de la religiosidad popular.

No voy a discutir aquí la idea de comunidad cerrada —o corporada-, pues este tipo de simplificaciones ya se ha cuestionado demasiado ${ }^{4}$. Sin embargo, es necesario decir que gran parte de la reflexión en

\footnotetext{
${ }^{2}$ No nos referimos en este trabajo a la esfera pública como espacio metatópico y donde ocurre la discusión de manera racional como lo plantea Habermas (2011) y lo retoma Taylor en su obra sobre los imaginarios sociales modernos. Sino a algo mucho más simple, en cuanto tiene que ver con un espacio específico donde están ocurriendo cambios importantes y definitivos. Guerra y Lemperiére (1998) parten de una distinción similar entre esfera pública como un espacio abstracto e inmaterial y los espacios públicos concretos — "la calle y la plaza, el Congreso y el palacio, el café y la imprenta" - . Para ellos, "los encuentros y las modalidades más intelectuales y etéreas de la comunicación y del intercambio de opiniones se producen en el espacio compartido de las relaciones personales, del vecindario, del parentesco y de la pertenencia a las mismas instituciones" (p. 10).

${ }^{3}$ De antemano sabemos que la existencia de una sociedad plural y estratificada es una condición para poder hablar de un espacio público, al menos así lo refiere el mismo Habermas cuando especifica que se trata de una categoría propia de la sociedad burguesa.

${ }^{4}$ Entre las argumentaciones antropológicas más contundentes, por ejemplo sobre el modelo de la comunidad cerrada de Los Altos de Chiapas, están los trabajos de Jan Rus (2012) y Robert Wasserstrom (1989), y de ambos en conjunto, que muestran claramente cómo el fortalecimiento del sistema de cargos políticos y religiosos estuvo relacionado con el control que ciertos grupos locales ejercieron sobre los recursos de una gran parte de la población que regularmente bajaba a emplearse a las fincas cafetaleras. De hecho,
} 
torno a esta problemática se ha estructurado sobre nociones muy básicas de progreso, modernidad, aislamiento, tradición, que generalmente se utilizan como principios excluyentes. Me parece que un excesivo apego a una idea estrecha de la modernidad y lo secular nos ha llevado a lamentarnos o bien a sorprendernos por sus impactos des-estructuradores en los llamados "sistemas tradicionales", pero no a comprender cabalmente las distintas maneras de "ser moderno" de las sociedades comúnmente denominadas "tradicionales". Lo que significa entender cómo éstas asimilan las transformaciones sociales y políticas que bajo la categoría de lo "moderno" o lo "secular" se viven al menos desde hace dos siglos.

En este trabajo, sólo señaló algunas de las tendencias más evidentes sobre diversificación, pluralismo y diferenciación en las comunidades michoacanas que cualquier estudio etnográfico debería tomar como punto de partida, para posteriormente ocuparme de la incidencia de las prácticas religiosas en el espacio público contemporáneo en localidades rurales.

\section{Breve recuento de la modernización en las comunidades michoacanas}

El objetivo de este apartado no es realizar un pormenorizado recuento histórico, lo que nos ocuparía demasiado espacio, sino sólo señalar los puntos sobresalientes que aparecen a lo largo del proceso de construcción del Estado mexicano en esta región y que aún en la actualidad resultan significativos para comprender la naturaleza histórica de las comunidades michoacanas. A grandes rasgos los procesos de cambio y diferenciación en las comunidades michoacanas se pueden agrupan en tres rubros:

\section{Procesos de diferenciación}

En las comunidades michoacanas, los procesos de diferenciación

desde los ańos sesenta y sobre todo en las décadas siguientes que se reflexionaba sobre la pérdida del aislamiento de los pueblos originarios y su avasallamiento por el progreso se tenía claridad sobre el tema. Las mismas tesis de la CEPAL sobre la dependencia mostraban que el mismo capitalismo al expandirse generaba una gran desigualdad y, por consiguiente, poblaciones dependientes y "atrasadas". 
económica y política se disparan a fines del siglo XIX y después de la aplicación obligatoria de las leyes de reforma y la privatización de tierras comunales. De entonces a la fecha se desprenderán varios problemas que enunciaré brevemente porque persisten hasta el día de hoy. El primero tiene que ver con indefinición de los límites entre comunidades y el control y manejo de los recursos forestales, en alguna medida la principal riqueza de las comunidades de la meseta purhépecha (Zárate, E., 2011). Este tema se hace visible a partir de la segunda mitad del siglo XIX, cuando se pretenden definir las fronteras entre comunidades de manera precisa, lo que hasta la fecha ha resultado prácticamente imposible. Además, desde fines del siglo XIX a las primeras décadas del XX, es decir, durante el periodo conocido como "porfiriato", grandes empresas concesionarias se aprovecharon de los recursos con pocos o ningún beneficio visible para las localidades. Luego, durante gran parte del siglo XX grupos de las mismas comunidades, o ajenos a ellas, hicieron un uso intensivo de los recursos forestales en las zonas en disputa o indefinidas (Espín, 1986; Vázquez, 1992; Zepeda 1998). Vinculada a la explotación de los bosques, aparecen a fines del siglo XX y con gran notoriedad en estas primeras décadas del XXI, las bandas de taladores. Un actor que tendrá una presencia notable en la actualidad porque se vinculará al crimen organizado — que armados y con amenazas despojan de sus recursos a las comunidades-. En cierta medida se trata de jóvenes desempleados, que al amparo de las indefiniciones de límites han hecho de esta actividad clandestina su ocupación. Y quienes, en la actualidad, no encuentran sino en la depredación de los recursos comunales un medio de vida.

También desde esa época a la actualidad, han existido al interior de las comunidades ciertas familias que acaparan importantes extensiones de tierras cultivables con base en el préstamo o el comercio. La revuelta etno-agrarista que ocurrió en las décadas de los setenta a ochenta del siglo pasado, lo que pretendía, en gran medida, era una recomunalización de las tierras y una redistribución de los bienes de los particulares al interior de las comunidades, fueran originarios o, sobre todo, foráneos. La gran mayoría de las comunidades tuvo un éxito limitado en la recuperación de tierras, justamente porque en algunos casos se tenían documentos de 
propiedad originados a principios de siglo. Como hemos mostrado en otros trabajos la principal consecuencia de este movimiento se dio en los ámbitos culturales y políticos, en los que sí ocurrió una redistribución del poder, se crearon nuevas normativas para limitar el autoritarismo de las personas que accedían a cargos públicos, se reivindicó la asamblea comunal, se exaltó la cultura local y se reforzó la identidad étnica como forma de participación política (Zárate, E., 1993 y 2002).

Si bien se han detonado nuevos procesos de acumulación, sólo en las comunidades más grandes, generalmente las cabeceras municipales, son visibles marcadas diferencias sociales y de clase. No así en la mayoría de las comunidades en las que procesos de diferenciación aparecen bastante mediados por la cultura de las relaciones sociales que inhibe el despliegue de claras diferencias. De los años ochenta a la fecha y luego de la implantación del modelo neoliberal se han generado nuevos procesos de diferenciación - y acumulación - que tienen que ver con la conversión de grandes zonas forestales en huertas de cultivos comerciales, principalmente aguacate; la aparición de empresas y proyectos comunales con financiamiento, y el aumento notable de la migración interna e internacional (Zárate, E., 2005 y s/f). Además, como ya mencionamos, también emergió un sector que se mantiene entre la informalidad y la ilegalidad. Entre estas capas sociales encontramos grupos con distintos proyectos de vida y comunidad, entre ellos una buena cantidad de profesionistas y migrantes, bastante visibles en todas las localidades, quienes junto con otros actores, permanentemente están generando distintos discursos culturales de comunidad y organización, sea de crítica, modernización y cambio, sea de mantenimiento y reforzamiento de las costumbres y tradiciones; en algunos casos también de "cierre" o de apertura ante ciertas tendencias, actores o proyectos. Esto es por supuesto una descripción muy general, pero para cada una de estas afirmaciones se podría recurrir a casos particulares.

Otro elemento que aparece como parte del proceso de modernización de las comunidades michoacanas es el conflicto social.

\section{Conflicto social}

Igualmente podríamos pensar y analizar el conflicto como un elemento 
endémico en las comunidades indígenas modernas. ${ }^{5}$ Aparece de manera clara en los documentos de fines del siglo XIX, entre quienes lucharon y utilizaron diferentes estratagemas para evitar el reparto de las tierras comunales y aquellos que se apresuraron a privatizar sus parcelas. También entre quienes defendían las tierras de las cofradías que servían para financiar los cargos y quienes deseaban repartirlas. Luego, desde los años veinte y hasta principios de la década de los cincuenta del siglo veinte, este conflicto interno se repetirá bajo las categorías de agraristas contra cristeros o sinarquistas. Unos, con apoyo del gobierno revolucionario buscando la formación de ejidos y el reparto de tierras en manos de particulares o de la comunidad, y otros defendiendo la propiedad comunal y las llamadas "tierras de la iglesia". Conviene detenernos en este punto por las implicaciones que estos eventos tuvieron en el proceso de secularización, diversificación del campo social y modernización de las mismas comunidades y que son visibles aun en la actualidad.

Este conflicto se manifestó y tuvo repercusiones prácticamente en todas las comunidades michoacanas, sin embargo, en muchas alcanzó tintes excesivamente violentos y radicales. Como en Carapan (Saénz, 1992), Charapan (García Mora, 1975), Naranja (Friedrich, 1981 y 1991), Tiríndaro (Friedrich, 1981; Solís, 2012), Puácuaro (Hernández, 2004), Tzurumútaro (Zárate, E., 1992), entre otras. Sin duda, en algunas comunidades se vivió como una especie de "modernización forzada". Una especie de "pogrom", que implicaba no sólo el reparto de tierras de las pocas haciendas en la región y de los propietarios particulares, sino también el impulso a la educación pública y los valores "cívicos", la integración de los indígenas, el cierre de las iglesias y el ataque directo a las organizaciones religiosas. Tal como lo narra Saénz (íbid.), durante su experiencia de campo en la región de la Cañada de los Once Pueblos. Prácticamente la abolición de la pluralidad en pos de una sociedad laica —algunos decían "atea"—, de campesinos —idealmente "mestizos" - organizados en sindicatos y otras agrupaciones de carácter cívico y oficial (Boyer, 2003). Se trató de una imposición por

\footnotetext{
5 Tal como lo plantea Vázquez (2012), para quien el conflicto en las comunidades indígenas es parte de su estructura.
} 
la fuerza del secularismo y cierta versión de la modernidad. En los años álgidos del conflicto se saquearon las iglesias y en algunas comunidades se quemaron los santos (Becker, 1994; Guerra, 2002), o los aventaron al lago, o algunos particulares se apropiaron de imágenes. Los edificios parroquiales se convirtieron en escuelas, internados o salas de juntas de los ejidatarios, como es visible hasta el día de hoy en localidades como Naranja, Cherán, Tzurumútaro o Puácuaro.

Durante estos años se perdió gran parte de la riqueza artística de las comunidades, como lienzos, cuadros y esculturas de imágenes religiosas. Los grupos agraristas fueron no sólo apoyados sino impulsados por el mismo Estado, que de esta manera pretendía restarle fuerza al poder de la iglesia en las comunidades rurales y crear un nuevo ciudadano, absolutamente alejado de los valores religiosos. Las consecuencias sociales además de las señaladas fueron la implantación de fuertes cacicazgos en las localidades, el asesinato selectivo de opositores y un sistema de organizaciones corporativas no religiosas, articuladas al partido oficial, la principal en el estado fue la Confederación Revolucionaria Michoacana del Trabajo. Además en algunas comunidades aparecieron otras denominaciones religiosas de corte protestante y en general se desestructuró el sistema de cargos religiosos que prácticamente en todas las comunidades tuvo que ser reorganizado en las décadas posteriores (Zárate, E., 1992; Hernández, 2004).

El radicalismo agrarista se debilitó en los años cincuenta cuando el Estado mexicano entra en la senda de la modernización económica. Entonces el poder absoluto de los caciques se modera y se permite la libertad de cultos. La Iglesia mexicana y el Estado pactan un acuerdo llamado "modus vivendi". No obstante en un régimen de partido único o de "partido hegemónico", la estructura corporativa se mantuvo vigente por años, no será hasta los noventa que las libertades política y de organización sean viables en el estado.

Si bien las libertades cívicas se habían ampliado un poco con la reapertura de las iglesias, quedaron subordinadas al discurso de la justicia y a los programas y políticas sociales, muy vinculados al funcionamiento de las organizaciones oficiales. En gran medida la mayoría de los conflictos políticos y sociales que aparecen desde los sesenta hasta 
los ochenta del siglo veinte serán por el control de los programas sociales y las candidaturas para puestos públicos al interior del partido hegemónico, entre distintas organizaciones o facciones dentro de las organizaciones oficiales. ${ }^{6}$ Este sistema de revueltas cíclicas que prevalecía en toda la región se quebrará con la emergencia de una organización de comuneros independiente a fines de los setenta (Vázquez, 1992; Zárate, E., 1993, Zárate, M., 1998; Zepeda, 1998) y finalmente con la ruptura al interior del partido oficial a fines de los ochenta y la emergencia en el estado del movimiento, encabezado por Cuauhtemoc Cárdenas, quien había sido gobernador del estado, denominado "neocardenismo".

\section{Pluralismo y alternancia política en una sociedad secular}

¿Que ha ocurrido de los ochenta a la fecha en términos del pluralismo y la ampliación de las libertades políticas y civiles, y del mismo proceso de secularización de las comunidades indígenas?

En las zonas rurales del estado, el pluralismo político por fin se hizo realidad. Si bien existían antecedentes de alternancia política a nivel municipal, como ocurrió a principios de los años ochenta, con la emergencia del panismo en algunas cabeceras municipales, en las zonas propiamente campesinas ésta no se hizo realidad sino hasta la década de los noventa. En los primeros años de la alternancia hay un claro volcamiento de la población hacia el neocardenismo y el partido que de éste emerge. Aunque en la mayoría de las comunidades lo que ocurrió fue la ruptura de antiguas lealtades, filiaciones políticas y redes de colaboración y clientelazgo, quizá porque la idea que se tenía era la de seguir actuando corporativamente, aunque bajo otras siglas. En los principales municipios indígenas del estado, en la década de los noventa, aparece un claro bipartidismo. Elección tras elección ganase quien ganase irremediablemente surgían violentos conflictos postelectorales. Durante toda la década de los noventa después de cada elección seguía un periodo de reclamos de los perdedores, en ocasiones enfrentamientos violentos y luego la intervención del gobierno federal y los acuerdos entre grupos. A nivel del gobierno del estado sucede algo

\footnotetext{
${ }^{6} \mathrm{El}$ trabajo que mejor muestra los procesos que estaban aconteciendo en esta época es el de Jesús Tapia (1992).
} 
similar, toda esta década la gubernatura estuvo ocupada por interinos nombrados por el gobierno federal. Quienes luego de que asumían el poder y con el fin de mantener la gobernabilidad debían establecer una serie de alianzas y compromisos con los poderes fácticos, incluyendo sectores que se mantenían en la informalidad. En el inicio del nuevo milenio, la llegada de un gobernador legitimado por las urnas, de un partido de oposición, y la renovación del gobierno de oposición por un quinquenio más, trajo consigo una serie de reacomodos y rupturas que agudizaron los procesos de diversificación y fragmentación que ya venían ocurriendo. ${ }^{7}$ De tal manera que en aquellos municipios en los que las disputas se daban entre dos fuerzas aparecieron otras opciones políticas, generalmente conformadas por desplazados o inconformes con el manejo de recursos. Es evidente que en la época actual el pluralismo político a nivel local está relacionado con nuevos objetivos de los grupos de interés, como el control de recursos para obra pública. Lo que siempre termina beneficiando económicamente a algunos personajes y excluyendo a otros.

La dinámica de divisiones, conflictos y posteriores acuerdos de reparto del poder, que se vivió en los ańos noventa, produjo, en las comunidades indígenas, el fin de las lealtades a las siglas partidistas y en algunos lugares el rechazo a participar en los procesos electorales formales. En la mayoría de las comunidades los partidos se convirtieron en cascarones vacíos con diferentes ofertas a ciertos sectores de la población tendientes a la conformación de clientelas políticas. Cada vez resultará más evidente que las estructuras partidarias tanto nacionales como a nivel del estado responden a sus propios intereses, tienen su propia agenda y están más preocupadas por mantener sus puestos y privilegios que por lo que acontece localmente, entre otras cosas, en los últimos años el control de la extrema violencia, que se convirtió en uno de los temas del debate público, no sólo local sino nacional.

De tal manera que aun cuando el pluralismo y la alternancia sean una realidad en los municipios y comunidades indígenas, la desconfianza y el resentimiento ante las instituciones políticas han crecido de manera

\footnotetext{
7 Nos referimos a los gobiernos estatales de Lázaro Cárdenas Batel, 2000-2006, y Leonel Godoy, 2007-2012.
} 
notable. Esto no sólo es visible en el caso del municipio de Cherán y la comunidad de Nurío que rechazan a los partidos y a los organismos electorales y ahora se gobiernan por "usos y costumbres", sino en otras comunidades y municipios que desde hace varios años han formado o le han dado formalidad a las asociaciones llamadas "Consejos", que agrupan a las personas con "prestigio" o notables de las comunidades y que intervienen ante ciertos eventos o coyunturas que consideran "amenazas" para la comunidad. Éste es sin duda uno de los elementos que le ha dado fuerza al movimiento de Cherán, porque a diferencia de otros lugares, su policía comunitaria y los encargados de diferentes áreas y tareas — como las rondas o guardias - están subordinados al Consejo. Organismos de este tipo ya existían desde los noventa en localidades como San Jerónimo, en el municipio de Quiroga; Nurío, perteneciente al municipio de Paracho; o Tingambato, cabecera del municipio del mismo nombre. En este último caso se trata de una asociación civil, denominada "Consejo para la Conservación de las Tradiciones de Tingambato", conformada por personas que cuentan con prestigio social en la población. No pertenece a la estructura municipal, pero sin duda ejerce una muy importante influencia en el quehacer cultural, social y político de la población. Desde los años noventa, impulsados por grupos de profesionistas e incluso por los mismos sacerdotes locales, existieron intentos por restablecer los "consejos de principales". Sin embargo, ha sido en los últimos ańos y ante la amenaza de los grupos criminales que estos consejos han adquirido un papel protagónico. Principalmente porque legitiman la actuación de las policías comunitarias o rondas de vigilancia por encima de las facciones políticas locales.

Lo anterior no es sino una muestra de cómo se ha ido perdiendo la confianza, que afloró a fines de los ochenta, no sólo en las instituciones políticas sino en los mismos procedimientos electorales. Sin este elemento es difícil que un sistema democrático funcione de manera óptima, ya que tiene que ver con que la gente sienta que es parte del proceso, que son escuchados y que su punto de vista será tomado en cuenta (Taylor, 2011). Este último tema se vincula con la preocupación por la intervención en el espacio público de organizaciones y discursos no seculares. 
Además en el caso de Michoacán otro elemento añadido sería el descrédito en que ha caído la política local a tal grado de volverse indistinguible lo legal de lo ilegal. En la actualidad, llegar a ocupar un cargo público no es cuestión de prestigio, sino de movilización de recursos, conformación de clientelas e inversión directa, como se dice "gana quien meta más lana". No sólo se percibe la relación que los políticos guardan con personajes o grupos ligados a la delincuencia, sino que se ve a los políticos locales como depredadores de recursos que son considerados como "de todos". Cuando los políticos mantienen una clara filiación partidista su actuación se ve tamizada por los intereses del propio grupo partidista. De ahí que en esos términos las localidades no sólo estén divididas, sino que continuamente se esté cambiando de partido político en la administración y aparezcan nuevas opciones en la escena pública local. En gran medida la decadencia de las ideologías políticas, que hasta los años noventa del siglo pasado organizaban la vida pública ha permitido la ampliación del espacio de expresión de las religiosidades públicas. No obstante, a pesar de que existen múltiples problemas de seguridad y conflictos y divisiones de carácter político, cuando aparecen los temas religiosos — sean por el control de una imagen, sean cooperación - desplazan todos los otros y se instalan en el centro de las preocupaciones de la gente común.

En resumen, tenemos una sociedad desigual, diversa y plural, en muchos sentidos, pero que no logra expresarse como tal en términos estrictamente seculares y tampoco encuentra en la ciudadanía política una forma de representación completa $-\mathrm{y}$ habría que decir ni auténtica- De ahí la continua construcción y reconstrucción de organizaciones colectivas. Su importancia radica en que hasta ahora se conforman mediante la participación de los sujetos en los asuntos que la colectividad considera fundamentales, es decir, los que imagina y define como parte de su identidad o ser, que son innegociables e intransferibles. Uno de ellos que muestra una gran continuidad y consistencia histórica es, sin duda, el cuidado y mantenimiento de ciertas imágenes religiosas y la organización de su culto. 


\section{Religiosidades públicas}

Entre los grandes temas de la geopolítica y de las ciencias sociales contemporáneas está la intervención abierta de la religión en los asuntos públicos de las sociedades seculares o de los Estados nacionales modernos. De tal manera que en las discusiones actuales cada vez toma más fuerza la idea de que es necesario repensar al estado secular, así como al mismo "espacio público" como ajenos a la religión y más bien considerar el hecho de que históricamente han mantenido un estrecho vínculo. Así lo plantean autores como Agamben, Asad, Taylor, Butler. Al menos el término "Estado de excepción" que se ha vuelto tan común desde fines de los noventa y sobre todo desde principios del siglo XXI — en tanto aparece relacionado con el tema de la seguridad, como preocupación fundamental de las sociedades actuales - tiene un fundamento en la idea teológica del soberano, como el que está por encima de la ley (Agamben, 1998; Schmitt, 2009).

Además desde la década de los ochenta ha quedado más que evidente la fuerza transformadora $y$, en ocasiones, extremadamente violenta, cuando no se cuenta con fuertes contrapesos civiles, que la religión puede llegar a tener en las sociedades modernas. Los ejemplos más socorridos son la revolución islámica en Irán, los sindicatos católicos en Polonia, las CEB en Nicaragua, Brazil, entre otros, y ahora la "primavera árabe" con sus revueltas en Libia, Egipto, Siria, donde los grupos de base religiosa tienen un papel protagónico. Ante la ausencia de una representación efectiva mediante las organizaciones políticas formales y un deficiente ejercicio de la justicia por parte de las instituciones seculares, como ocurre en muchos lugares y momentos, las organizaciones de carácter religioso pueden ocupar el espacio de la representación política.

Algunos de estos casos son los que toma José Casanova (1994), en su estudio ya clásico, para proponer el término de "religiones públicas". Lo que muestra es que las religiones en la sociedad contemporánea se han "desprivatizado". Han dejado de estar confinadas al ámbito de lo privado para incidir de manera directa en el espacio público. Sin duda el trabajo de Casanova representó un parteaguas en el estudio de la religiosidad y sirvió como punto de partida para repensar la 
importancia que la religiosidad tiene en el mundo contemporáneo y hasta dónde sus valores son compatibles o no con los de una sociedad secular o moderna.

Justamente en esta discusión y luego de la aparición de la magna obra de Taylor (2007) y de la importante obra antropológica de Talal Asad (2003) es que han surgido las críticas al trabajo de Casanova, sobre todo a su idea de "desprivatización". Se ha demostrado que la confinación de la religiosidad al ámbito estrictamente privado es más bien una excepción en las sociedades liberales, aun en aquellas industrializadas y plenamente seculares. Se trató de la formulación teórica de un ideal de modernidad, pero que difícilmente se encuentra en las sociedades contemporáneas. Aunque no citan mutuamente sus respectivas obras, si bien Asad cita un trabajo previo y preliminar de Taylor sobre secularismo, los dos autores coinciden plenamente en que la idea de un Estado secular o de espacio público secular como excluyente o ajeno a lo religioso es una interpretación equivocada o errónea del término. ${ }^{8}$ También en que es necesario diferenciar entre secular, secularismo y secularización, pues no significan lo mismo y no tienen las mismas consecuencias en el espacio público. Rastrean en las genealogías de conceptos como secular, Estado nación, contrato social, bien público, soberanía, para mostrar cómo las ideas religiosas y las cívicas confluyen y se excluyen, convergen y chocan a lo largo de la historia del pensamiento moderno, el mismo que da origen a la idea de Estado laico o secular.

Lo más importante es reconocer que existen varias definiciones de secular, Taylor ofrece tres: la que establece una clara separación entre el Estado y la religión; la que separa lo público de lo privado, y la tercera que propone que la creencia religiosa se convirtió para los sujetos modernos en una opción entre otras. Es decir, que legitima el pluralismo religioso. No sólo se trata de elegir una entre varias opciones religiosas, sino entre varios sistemas de creencias, entre los que pueden competir incluso con la democracia representativa. Esta última es la más significativa para entender la persistencia, y en algunos casos la irrupción, de

\footnotetext{
${ }^{8}$ Si bien se podría considerar a Taylor como un filósofo católico-hegeliano y a Asad como un constructivista.
} 
la religión en el ámbito público sin entrar en contradicción con las instituciones modernas y seculares, en ocasiones, incluso complementándose. Mantener una fe o creencia sería una posibilidad de los sujetos modernos entre otras opciones como la de no creer o incluso mantener una posición neutra frente a las manifestaciones religiosas de otros.

Esta propuesta implica dejar de lado la perspectiva durkheimiana, que opone pensamiento religioso a pensamiento racional - o modernoy aceptar de manera definitiva que su persistencia bajo diferentes formas es resultado justamente del avance de la racionalidad. De hecho dice Asad que no es posible pensar lo secular sin lo religioso, o que el pensamiento secular no existiría sin el religioso. En algunos lugares y épocas, como en gran parte del Occidente de México en las primeras décadas del siglo XX, mantener y defender esa actitud resultaba incluso más peligroso que declararse abiertamente secular. En las comunidades contemporáneas, en gran medida legitima las acciones organizativas que permiten su reproducción social. Para los sujetos modernos sería un aspecto igual de importante que el reconocimiento político o social. Tema sustantivo cuando tenemos en consideración poblaciones con altos índices de movilidad y que no encuentran fácilmente ni el reconocimiento ni la satisfacción espiritual que la participación en los rituales y en las organizaciones comunales les otorgan de manera clara. Quien pertenece a una comunidad y pretende mantener activa su membresía a ésta, no asiste a las fiestas sólo por diversión y esparcimiento, sino básicamente por compromiso y solidaridad. Lo que se manifiesta mediante la cooperación y la participación activa en la organización del culto.

Se participa en la organización no sólo a través de redes familiares, sino también de la cooperación monetaria, en especie o trabajo. Pero también la simple asistencia es una muestra de interés y, en momentos de conflicto, de apoyo a los responsables de llevar el culto. En esta época la participación en una celebración o culto religioso en ningún caso representa una actitud desinteresada, por el contrario siempre implica el ejercicio libre y la toma de posición frente al abanico de creencias que se ofrecen a las personas. 
Los procesos sociales que enunciamos antes, y en los que la religiosidad tuvo un papel importante, en la transformación de la sociedad y en la reconfiguración del espacio público fueron posibles porque existía una religiosidad viva asentada en firmes instituciones y prácticas, y legitimada en la experiencia misma de las personas, incluso algunos antropólogos dirían en un razonamiento lógico (Lurhman, 2012). Se trata de un proceso un tanto similar al que ocurre en la India (Canell, 2010), donde si bien el gobierno es secular, la cultura está fuertemente enraizada en valores religiosos o espirituales. Lo importante es que son estos valores los que le dan soporte a los comportamientos y expresiones cívicas y no necesariamente los valores de la democracia occidental.

¿A que nos estamos refiriendo? ¿Qué ofrecen las prácticas religiosas actuales, en particular a las sociedades locales diferenciadas inmersas en acelerados procesos de cambio y diferenciación social, y en un contexto de violencia e incertidumbre?

\section{Las organizaciones religiosas en una sociedad [post]secular}

A mediados del siglo pasado y cuando aún se pugnaba por "abrir" e integrar a las comunidades indígenas a la nación - $\mathrm{O}$ al desarrollo nacional — se propuso que los sistemas de cargos religiosos persistían porque tenían [en el sentido durkheimiano] una función redistributiva de la riqueza y por consiguiente igualadora al interior de la comunidad. Por lo mismo, constituían uno de los mecanismos más eficientes para redistribuir el prestigio y mantener a la comunidad aislada o cerrada y sin que aparecieran contradicciones que impulsaran el cambio social. Se trataba además de una jerarquía en la que aparecían mezclados lo civil y lo religioso, y en la que se ascendía según el prestigio logrado mediante el financiamiento de los cargos. En términos generales éste era el modelo para las comunidades indígenas de Mesoamérica. Aunque mostraba variaciones al interior de esta amplia área cultural, se expresaba de manera ejemplar o arquetípica en Los Altos de Chiapas y en algunas regiones de Oaxaca y Guatemala. Aunque era de origen colonial, tenía una gran vigencia en estos lugares. ${ }^{9}$ Ya mencionamos la

\footnotetext{
${ }^{9}$ H. Favre (1973) planteaba que el estudio antropológico de Los Altos de Chiapas, por ejemplo, representaba una posibilidad para entender a la sociedad colonial.
} 
crítica que Wassertrom y Rus hicieron a dicho modelo en Los Altos de Chiapas. Para el caso de Michoacán, Pedro Carrasco (1976), quien había realizado su investigación sobre la religiosidad popular a mediados del siglo veinte en los años inmediatamente posteriores al conflicto religioso, señalaba que los cargos habían entrado en una severa crisis y estaban a punto de desaparecer. Carrasco no habla de sistema ni de jerarquía religiosa, como tampoco lo hacía Aguirre Beltrán en su obra Formas de gobierno indigena. Simplemente subrayaba que el avance del proceso de secularización es tal que, tarde o temprano, desaparecerían esas manifestaciones. El gasto excesivo en su financiamiento había dejado a algunas familias prácticamente en ruinas, a lo que se aunaban las críticas - de maestros, agraristas e incluso de los mismos sacerdotespor el gran gasto que implicaban. La situación de pobreza era tal que la mayoría de las personas no querían tomar un cargo y a quien le tocaba debía irremediablemente vender propiedades o endeudarse en grandes cantidades y por varios ańos. Más que una responsabilidad eran un gran peso que en ocasiones terminaba aplastándolos.

Pedro Carrasco también identifica la particular dinámica de los cultos michoacanos populares, algunos santos patrones y otras imágenes pierden popularidad o caen en desuso, mientras que otras, decía, como los Cristos milagrosos, toman un auge inusitado, de tal manera que se convierten en la fiesta principal de algunas comunidades desplazando en esplendor a los santos patrones. Esta dinámica ha continuado y es posible observar como nuevos cultos van ganando mayor presencia en el ámbito público en los últimos años. Sobre todo por varias razones. Entre otras porque se insertan en los procesos de cambio que ha vivido esta sociedad en las últimas décadas.

Lo que encontramos en la actualidad es un calendario festivo excesivamente cargado de celebraciones, el notable auge que algunas fiestas han adquirido, el aumento en el gasto y la renovación constante de los mecanismos locales de solidaridad y cooperación, que si bien frecuentemente no abarcan a la comunidad completa, por los conflictos sociales que les son inherentes, sí representan formas efectivas de organización comunal. Vemos en los cultos populares contemporáneos y sus celebraciones un esplendor como no se había visto con 
anterioridad, una participación masiva en los sistemas de cooperación y un compromiso de grandes cantidades de personas. "Antes, esta fiesta era chiquita, que esperanzas que se hiciera como ahora, para la Navidad se daba de comer a las personas con una res, ahora se matan más de diez", nos comentó una señora de Tingambato. Otra de Aranza, donde las fiestas de la Navidad duran toda la semana, nos dijo que se sacrifican como 40 cerdos.

En Carapan, la carguera nos comentó que sólo la banda para los 5 días de la fiesta de Navidad le cobrará 75 mil pesos — que está pagando en abonos - además de que sacrificarán varias reses, para ofrecer la comida, durante los días que duran las celebraciones. En gran parte de las comunidades las fiestas de Navidad duran más de tres días, sin incluir la posadas, varias procesiones por la comunidad, visitas a capillas y a casas particulares, el Año nuevo y la fiesta de Reyes. Aunque en algunas comunidades forman un contínuum de fiestas de la temporada.

En la actualidad el ciclo de fiestas de la imagen del Niño Dios cubre una buena parte del año, el principal periodo inicia en el mes de diciembre —en algunas comunidades el periodo de las posadas se ha extendido a todo el mes, como ocurre en Santa Fe de la Laguna, debido a la gran cantidad de solicitudes para realizarlas - hasta el 30 de abril, Día del Niño. Las principales fiestas son Navidad, 24 de diciembre; Santos Reyes, 6 de enero; Candelaria, 2 de febrero, y Día del Niño, 30 de abril. En aquellas comunidades donde el Niño se ha convertido en la imagen principal, por encima del Santo Patrón, como en Tingambato, San Ángel Zurumucapio, Sevina, Aranza, entre otras, además interviene en el resto de las celebraciones que se llevan a cabo prácticamente todo el ańo. En Tingambato, participa en las fiestas de los barrios, en que va de visita a las capillas y a las casas de los cargueros; en la del Santo Santiago, el Santo Patrono que se realiza en julio; y en la que desde hace algunas décadas es la fiesta más grande, la del Cristo Redentor, que se celebra el 14 de enero y que también dura toda la semana. Los cargueros del Niño participan en las procesiones, misas y ofrecen de comer a los visitantes. En estas comunidades cada familia de cargueros construye o manda construir su propio altar - en ocasiones se trata de estructuras de madera bastante elaboradas, con imágenes 
labradas y columnas, además de varios niveles-, cotidianamente cambia los arreglos florales, imprime calendarios, invitaciones y carteles con la imagen del Niño dando la bienvenida y la lista de las actividades a realizarse durante los festejos del Cristo Redentor. Todos los días el altar está adornado con flores naturales frescas. Muchos de los arreglos florales los lleva la gente que acude a visitarlo al igual que veladoras y juguetes, otros los mismos cargueros deben proporcionarlos. En cada fiesta se ofrece de comer a todos los asistentes. Por eso se dice, en algunos lugares, como en Santa Fe de la Laguna, que si acaso no es el cargo más importante sí el más pesado, por el gran gasto que conlleva.

En gran medida, en la región, las fiestas se han renovado debido al financiamiento de migrantes que mantienen una relación estrecha con su comunidad. También se han "modernizado" por los nuevos ingredientes que introducen estos actores. Por ejemplo, en las listas de cargueros de varias comunidades de los últimos cuatro ańos, siempre aparecen además de migrantes, profesionistas como médicos, abogados o prósperos agricultores. Los cargueros del Niño Chichihua de Aranza del año 2014, residentes en Estados Unidos, dejaron a una de sus hermanas encargada de la imagen en su pequeña capilla; el carguero principal de Comachuén de 2014 era un médico que tenía su consultorio en la comunidad vecina de Capacuaro, su hija también era médica y otro de sus hermanos arquitecto. Las familias de los cargueros de Tingambato de 2012, 2013 y 2014, contaban entre sus miembros a varios profesionistas, principalmente maestros, arquitectos, abogados y también migrantes residentes en Estados Unidos. Los cargueros del Niño de Chilchota de 2014 también eran profesionistas avecindados desde hace décadas en la ciudad de México.

Lo anterior por mencionar sólo el culto al Niño, pero en las fiestas principales es aún más común la participación de migrantes y profesionistas. Como sucede en el caso de San Jerónimo y su fiesta patronal. En aquellas comunidades, donde la migración tiene ya una larga temporalidad, los cambios y adaptaciones han sido más significativos. Tal es el caso de San Jerónimo Purenchécuaro, donde las festividades locales forman parte ya de esa amplia comunidad transnacional que se ha conformado en las últimas décadas. Hasta fines de los ochenta, entre 1987 
y 1988 había cuatro cargueros, dos por cada mitad del pueblo, entre los dos de cada mitad se cooperaban para pagar una banda, entonces sólo había dos bandas que amenizaban la fiesta y se colocaban a cada lado de la entrada principal de la Jefatura de Tenencia. En la víspera se realizaba una serenata que en ocasiones incluía música clásica para banda como overturas y marchas. Después según iba transcurriendo la noche continuaban con música popular y ya casi en la madrugada con los sones y abajeños de la región. A partir del año 1988 los cargueros empezaron a venir de fuera, principalmente de Estados Unidos - Oregón, Chicago- - desde entonces cada uno contrata su propia banda. De esa fecha a la actualidad, en la fiesta principal dejaron de ser dos bandas para convertirse en cuatro a cual más de festiva y sonora, las mismas que se distribuyen entre la plaza principal y la cancha de básquetbol, aledaña.

En algunos casos, como cada carguero puede financiar por sí mismo casi todo el gasto de la fiesta, no echan mano de las redes de apoyo en su totalidad. Para mediados de los noventa se decía claramente en San Jerónimo: "los cargueros del norte vienen, hacen su fiesta y se van... y ya no vuelven a cooperar ni con sus familiares ni con otros cargueros", esta situación, aunque no es tajante, pues hay quienes sí cumplen con ciertas obligaciones, prácticamente se ha institucionalizado. Lo mismo ha sucedido con la quema de los castillos. De alguna manera antes se guardaba cierto orden, sólo se quemaban dos castillos y las bandas se alternaban para tocar. Ahora se van quemando los castillos seguidos, cada carguero con su banda paga su propio castillo y luego de la quema se retiran. En ocasiones las otras bandas siguen tocando por lo que, dice la gente, "aquello es un verdadero barullo". Desde entonces y por iniciativa de los jóvenes migrantes se estableció un baile popular en la cancha central del pueblo, amenizado por las mismas bandas que de noche cambian sus uniformes, instalan un templete con luces y sonido y se realiza un baile popular, como se dice, "principalmente para la juventud". Entones salen a relucir las nuevas personalidades festivas de hombres y mujeres jóvenes, quienes además de portar sus nuevos atuendos a la usanza norteña, también bailan y se comportan como cualquier otro joven de origen popular urbano. En el caso de San Jerónimo, se ha reafirmado el sistema de cargueros para todas sus fiestas 
con la participación de los migrantes, el gasto conspicuo se ha incrementado notablemente y los cambios son evidentes.

Es frecuente que se cambien las fechas de ciertas fiestas para dar lugar a la llegada de los "hijos ausentes" o que los cultos se festejen en las ciudades del interior del país y del extranjero. Por ejemplo, réplicas del Niño Chichihua de Aranza se celebran en Phoenix, Arizona, Cargueros: Víctor Gutiérrez y Baltazar Zacari (2010-2011); Colton, California, Cargueros: Familia Trujillo Macías (2012-2013); Los Angeles, California, Cargueros: Familia Mercado López (2013-2014); Colton, California, Cargueros: Familia Rentería Méndez (2014, 2015). ${ }^{10}$ También en la ciudad de Guadalajara, las familias originarias de Pamatácuaro mantienen varias réplicas del Niño y realizan celebraciones similares a las de su comunidad (Bayona, 2006). Por lo mismo se buscan "días movibles" y que la fiesta se celebre en fin de semana. Se podría decir que en la actualidad aquellas fiestas que de alguna manera permiten la vinculación de los migrantes o "paisanos" que viven fuera de la comunidad son las que tienen más afluencia y se celebran con mayor esplendor, como sucede ahora con la Navidad.

La vinculación de estos cultos con la migración es importante. De hecho nunca he conocido a ningún migrante que antes de emprender su viaje no se encomiende a alguna imagen. El testimonio de un joven migrante con ideas modernizadoras nos ofrece un buen ejemplo de las limitaciones que encuentra el pensamiento secular frente al religioso en estos contextos. Ante la pregunta de si asiste a las fiestas del Niño, dice:

pues a veces sí voy, pero a mí ese rollo como que me saca de onda, porque está bien que se haga algo, pero hay mucho gasto y aquí la gente no está para gastar tanto, yo luego iba a la iglesia los domingos en California y estaba bien porque nos juntábamos los hispanos y comíamos juntos, luego que puros michoacanos y así. Hasta hay que de cada pueblo los que se juntan, pero cada quien lleva algo, no es el gastadero que se da aquí. Yo creo que ya es mucho, pero cuando les digo a mis

\footnotetext{
${ }^{10}$ Información de la página: https://www.facebook.com/SantoNinoChichihua
} 
papás que le bajen hasta se enojan conmigo, yo nunca pediría llevar el cargo. [Aunque] aquí todos le tenemos mucha fe al Nińo, cuando pasé la primera vez mi mamá me puso un rosario que llevaba la foto así chiquita del Niño, yo sé que esa imagen me ayudó y me protegió mucho. Luego había un bato de aquí de Tingambato que lo agarró la ley y lo metieron al bote, yo le mandé el rosario para que lo protegiera porque querían darle cadena perpetua que porque dizque había matado a un policía, pero él no fue, fueron unos mayates los que se lo echaron, al final vieron en unas cámaras que había en la calle que él no había sido. Un día [él] hizo una carne asada en su yarda y me invitó para agradecerme por el rosario y me lo entregó, el bato decía que el Niño Dios era el que lo había salvado, ya luego un día me estaba bañando y se me reventó el rosario (entrevista, 0601 2013).

De ahí que las opiniones de los agentes modernizadores que recomiendan que se moderen en las celebraciones resulten difíciles de aceptar y adoptar por las satisfacciones personales y colectivas que trae consigo la creencia misma. Habría que preguntarnos, ¿quién puede negarse a participar tras un milagro? Sobre todo si la incertidumbre está por todos lados o resulta ser un componente fundamental de la vida social actual sea por los vaivenes económicos, sea por la violencia desbordada.

Estos cultos en términos generales permiten la integración y el reconocimiento de actores emergentes como profesionistas y migrantes que se han convertido en los principales promotores y patrocinadores de las celebraciones. Además de hacer visibles a otros sectores como las mujeres, que son las principales encargadas de sostener las fiestas y del cuidado de la imagen del Niño Dios, tanto en la vida cotidiana como durante las fiestas. En varias comunidades, donde la migración es muy pronunciada, incluso ocupan los cargos más importantes como el de Prioste o Juez. Si hay algún culto en que participen activamente las mujeres es en éste. Mantienen una relación estrecha e íntima con la figura del Nińo, se encargan de cuidarlo y darle un trato especial. Cotidianamente lo visitan, limpian el recinto, llevan 
flores y otras ofrendas, y están todo el tiempo "al pendiente"; durante las fiestas grandes contingentes de mujeres parientes, amistades y vecinas participan en la elaboración de alimentos y en la atención a los visitantes. Sus acciones, de alguna manera, tienen un contenido cívico explícito, que es básicamente mostrar en su comunidad hasta dónde se puede ser responsable de cuidar una imagen sagrada, que en algunos lugares es una verdadera reliquia de más de un siglo de antigüedad, sin duda encargo de gran magnitud para el universo local en que se desenvuelven estas personas. En el caso específico del culto al Niño Dios, también hace visible a los mismos niños. En cierto sentido se trata simbólicamente de una celebración de la infancia y en términos prácticos en varias de las fiestas se reparten de manera masiva dulces, juguetes, pasteles y gelatinas, porque es para el Niño.

Ya mencionamos la formación de consejos en varias comunidades. En Tingambato, en particular desde fines de los noventa, se creó el Consejo para la conservación de las tradiciones de Tingambato, justamente por un enfrentamiento entre la comunidad y el sacerdote que mediante ciertas artimañas pretendía mantener el control de la imagen del Niño Jesús, lo que hasta la fecha no ha logrado, porque se interpretó como una acción egoísta la de controlar la imagen y los recursos que ofrecen los visitantes. Esto debido a que se trata de un bien público que no pertenece a ninguna persona sino a la comunidad. El control de éste y la organización de su culto resultan fundamentales para otorgar sentido al proceso de comunalización que permite la integración de los distintos actores incluso los que residen fuera de la comunidad, como los migrantes. Fue necesaria la creación del Consejo para evitar la confrontación de individuos y familias particulares con el sacerdote, lo que provocó que se reforzara la autonomía del culto y el control de la imagen estuviera en manos de la comunidad. El Consejo es sin duda un importante referente en el mantenimiento del orden público, incluso en los momentos de mayor criminalidad organizaba, como el de Cherán, guardias nocturnas en los barrios. Se trata de una asociación civil conformada por personas de alta calidad moral, reconocidas por la comunidad, en la que participan señores de edad que han sido cargueros, aunque también hay algunos profesionistas adultos que, 
como en el caso de Cherán, intervienen en la política local, aunque sin una filiación partidaria clara. Mantiene una presencia y una vigilancia constante en los asuntos locales y en lo que podría denominarse muy ampliamente la moral pública. Es sin duda el referente que permite a las personas realizar las festividades, incluso algunos actos litúrgicos fuera o en franca confrontación con la Iglesia.

Por la gran cantidad de recursos que se consumen en cada celebración y a lo largo del año, por la considerable cantidad de personas que voluntariamente se involucran en las celebraciones, y por el ánimo de cooperación y ayuda que prevalece, este tipo de organizaciones resultan igual de efectivas en la vida pública que cualquier otra de carácter estrictamente secular, porque inciden directamente en la construcción del orden social, que al parecer está fuera de los intereses de los grupos políticos formales.

\section{Conclusiones}

Si bien el Estado laico y radical de la primera mitad del siglo XX atacó a la religiosidad popular, en particular el financiamiento de los cultos, el Estado neoliberal con menor compromiso social la percibe y promueve como necesaria para el mantenimiento del orden. Ambos han mostrado claras limitaciones en el tema del reconocimiento de sujetos colectivos y la impartición de justicia. Así el reforzamiento de redes y vínculos comunitarios, a través de la cooperación y la participación voluntaria, se convierte en un recurso estratégico fundamental en una sociedad secular, donde la pluralidad de opiniones y de opciones religiosas y políticas es también una realidad.

En las sociedades modernas se intentó por diversos medios recluir la religión al ámbito privado y dejar el espacio público como un ámbito estrictamente secularizado. Ahora sabemos que se trató de un proyecto que ha provocado innumerables conflictos. Las sociedades indígenas de una u otra manera y en distintas épocas históricas han resuelto la vinculación entre lo cívico y lo religioso a través de mecanismos como el compromiso, la responsabilidad, la cooperación y el reconocimiento público. En ambos casos lo que se ha pretendido es regular la intervención de la religión en los asuntos públicos. A lo largo del siglo XX y lo 
que va del XXI, los cultos católicos locales han servido tanto para ampliar el espectro de la convivencia social y salir o escapar del encierro de la civilidad radical y antirreligiosa o permitir la preservación de valores fundamentales para la convivencia frente a las presiones individualizantes del capitalismo neoliberal. Aunque como acontece claramente en los regímenes fundamentalistas puede llegar a negar la diversidad, la privacidad e incluso abarcar todo el espacio público.

Hasta ahora en las comunidades michoacanas el espacio que la religión "propiamente ocupa" ha estado mediado por los valores cívicos locales que hacen énfasis en la responsabilidad y la participación "voluntaria" en los asuntos comunitarios. No obstante se trata de un espacio donde lo cívico y lo religioso aparecen confundidos. Incluso en las acciones políticas contemporáneas, como aquellas encaminadas a lograr un gobierno comunal autónomo, aun cuando su discurso sea plenamente secular. De ahí que aún en la actualidad el estudio de los procesos de reconocimiento de formas de participación cívicas particulares debe considerar necesariamente la poca claridad discursiva en la que se exaltan valores como el comunalismo o la participación voluntaria libre de coerción en los asuntos públicos. Como hemos argumentado a lo largo de este trabajo tienen un claro contenido religioso que se renueva constantemente y es parte constituyente de los comunalismos modernos.

\section{Bibliografía citada}

Agamben, Giorgio, 1998, Homo Sacer, El poder soberano y la nuda vida, Pre-Textos, Valencia.

Aguirre Beltrán, Gonzalo, 1982, Formas de gobierno indígena, INI, México. Asad, Talal, 2003, Formations of the Secular, Christianity, Islam, Modernity, Stanford University Press, Stanford.

Bayona Escat, Eugenia, 2006, La ciudad como oportunidad y peligro. La comunidad inmigrante de comerciantes purépechas en Guadalaja$r a$, Tesis de doctorado en Ciencias Sociales, Ciesas-Occidente, Guadalajara, Jalisco.

Becker, Marjorie, 1994, “Torching La Purísima, Dancing at the Altar: The Construction of Revolutionary Hegemony in Michoacán, 
1934-1940”, en Gilbert Joseph y D. Nugent (editores), Everyday Forms of State Formation. Revolution and the negotiation of Rule in Modern Mexico, Duke University press, Durham and London.

Blasquez, Lidia, 2001, La identidad xochimilca a fines del siglo XX, Tesis de licenciatura, ENAH, México.

Boyer, Christopher, 2003, Becoming Campesinos. Politics, Identity, and Agrarian Struggle in Postrevolutionary Michoacán, 1920-1935, Stanford University Press, Stanford, California.

Butler, Judith, 2011, “¿El judaismo es sionismo?”, en Mendieta y Vanantwerpen (editores), El poder de la religión en la esfera pública, Trotta, Madrid, pp. 69-86.

Cannell, Fanella, 2010, "The anthropology on Secularism", Annual Review of Anthropology, vol. 39, pp. 85-100.

Casanova, José, 1994, Public Religions in the Modern World, The University of Chicago Press, Chicago.

Carrasco, Pedro, 1976, El catolicismo popular de los tarascos, SepSetentas, México.

Espín, Jaime, 1986, Tierra fría. Tierra de conflictos en Michoacán, El Colegio de Michoacán/Gobierno del estado de Michoacán, Zamora, Michoacán.

Favre, Henri, 1973, Cambio y continuidad entre los mayas de México, Siglo XXI, México.

Friedrich, Paul, 1981, Revuelta agraria en una aldea mexicana, FCE, México.

García Mora, Carlos, 1975, San Antonio Charapan. El conflicto agrarioreligioso en una comunidad de la Sierra Tarasca, Tesis de maestría, ENAH, México.

Guerra, Francois-Xavier y Annick Lemperiere et al., 1998, Los espacios públicos en Iberoamérica. Ambigüedades y problemas. Siglos XVIII-XIX, FCE, México.

Guerra Manzo, Enrique, 2002, Caciquismo y orden público en Michoacán, 1920-1940, El Colegio de México, México.

Habermas, Jürgen, 2011, "Lo político: el sentido racional de una cuestionable herencia de la teoría política", en Mendieta y Vanantwerpen (editores,), El poder de la religión en la esfera 
pública, Trotta, Madrid, pp. 23-38.

Habermas, Jürgen, 2011 b, Historia y critica de la opinión pública. La transformación estructural de la vida pública, Gustavo Gili, Barcelona, España.

Hernández, Claudia, 2004, "Estado, campo social y construcción de comunidad: El caso de Puácuaro, Michoacán, 1916-1936”, en Andrew Roth (editor), Recursos contenciosos. Ruralidad y reformas liberales en México, El Colegio de Michoacán, Zamora, Michoacán.

Luhrman, T. H., 2012, "A Hiperreal God and Modern Belief: Toward an Anthropological Theory of Mind", Current Anthropology, vol. 53, núm. 4, pp. 371-395.

Mendieta, Eduardo y Jonathan Vanantwerpen (editores), 2011, El poder de la religión en la esfera pública, Trotta, Madrid.

Rus, Jan, 2012, El ocaso de las fincas y la transformación de la sociedad indigena de los Altos de Chiapas, Cesmeca-Unicach, Tuxtla Gutiérrez, Chiapas.

Saénz, Moisés, 1992 [1936], Carapan, OEA-CREFAL, México.

Salles, Vania y José Manuel Valenzuela, 1997, En muchos lugares y todos los días. Virgenes, Santos y niños Dios. Mistica y religiosidad popular en Xochimilco, El Colegio de México, México.

Schmitt, Carl, 2009, Teología politica, Trotta, Madrid.

Solís, Jesús, 2012, Ser ciudadano, ser indio. Luchas politicas y formación del Estado en Nurío y Tirindaro, Michoacán, Colmich/Unicach, Zamora, Michoacán.

Tapia, Jesús (editor), 1992, Intermediación social y procesos politicos en Michoacán, El Colegio de Michoacán, Zamora, Michoacán.

Taylor, Charles, 2003, Las variedades de la religión hoy, Paidós, Madrid.

Taylor, Charles, 2007, A Secular Age, Belknap-Harvard, Cambidge, Massachussetts, and London, England.

Taylor, Charles, 2011, "Por qué necesitamos una redefinición radical del secularismo", en Mendieta y Vanantwerpen (editores), pp. 39-60.

Vázquez, Luis, 1992, Ser indio otra vez, Conaculta, México.

Vázquez, Luis, 2012, "Estructura y procesos políticos de la comunidad indígena moderna", en Guillermo de la Peña y Jorge Aceves (compiladores), Visiones múltiples. El Occidente de México desde 
la antropología y la historia, tomo 2, CIESAS, Guadalajara, Jalisco, pp. 555-570.

Wasserstrom, Robert, 1989, Clase y sociedad en el centro de Chiapas, FCE, México.

Zárate, Eduardo, 1992, "Procesos políticos en la cuenca lacustre de Pátzcuaro", en Sergio Zendejas (coordinador.), Estudios Michoacanos IV, Colmich, Zamora, Michoacán, pp. 205-232.

Zárate, Eduardo, 1993, Los señores de Utopía, El Colegio de Michoacán /CIESAS, Zamora, Michoacán.

Zárate, Eduardo, 2002, "Ciudadanía, comunidad y modernidades étnicas", en Marco A. Calderón et al., Ciudadanía, cultura politica y reforma del Estado en América Latina, El Colegio de Michoacán/IFE, Zamora, Michoacán, pp. 407-428.

Zárate, Eduardo, 2005, "La comunidad imposible. Alcances y paradojas del moderno comunalismo", en Miguel Lisbona (coordinador), La comunidad a debate. Reflexiones sobre el concepto de comunidad en el México contemporáneo, Colmich/ Unicach, Chiapas, Zamora, Michoacán, pp. 61-86.

Zárate, Eduardo, 2011, "Comunidad, reformas liberales y emergencia del indígena moderno. Pueblos de la Meseta Purhépecha (1869-1904)", Relaciones, vol. XXXII, núm. 125, pp. 17-52, El Colegio de Michoacán, Zamora, Michoacán.

Zárate, Eduardo, s/f, "Movimientos de población entrelos purhépechas", (mecanoescrito, entregado para su publicación).

Zárate Vidal, Margarita, 1998, En busca de la comunidad. Identidades recreadas y organización campesina en Michoacán, Colmich/ UAM-I, Zamora, Michoacán.

Zepeda, Jorge, 1988, Michoacán: sociedad, economía, politica y cultura, UNAM, México. 